\title{
KEePING THE ELDERLY COVERED
}

nfluenza still has significant morbidity and mortality in people over 65 years. The risk factors for death from influenza are age and underlying disease, and it is estimated that two-thirds of the population 65 years and over can be expected to have one or more chronic medical conditions. During influenza epidemics it is estimated that 80 per cent to 90 per cent of excess deaths are attributable to influenza or its complications.

Despite recommendations that everyone over 65 years be immunised yearly against influenza, ${ }^{2}$ it appears that coverage rates are less than optimal. Considering the proportion of elderly people in the community is increasing, a more energetic attempt to increase the coverage rate needs to be made.

Recent cases of tetanus highlight the need to increase the coverage rate of immunisation for this disease. Routine immunisation against tetanus began in 1954. There were, however, mass campaigns before that, most notably among servicemen in World War II. The four recent notifications for tetanus in NSW (1990-1991) have been in the unimmunised elderly, suggesting there is a pool of unimmunised people in this age group, especially those who did not serve in the armed forces. ${ }^{3}$

\section{METHODS}

For a four-week period from May 20, 1991, a survey was conducted through the General Practitioner Sentinel Surveillance network of South Western Sydney Area Health Services (jointly administered by the Department of General Practice and the Public Health Unit). A total of 20 general practitioners from various suburbs of South Western Sydney participated in the survey.

The doctors determined (by patient recall or the doctors' records) whether or not all patients 65 years and over had ever been immunised against tetanus and/or been immunised this year for influenza. This was irrespective of their reason for presentation to the doctor. It was also recorded if the patient was suffering from influenza as determined by a clinical definition. ${ }^{4}$

\section{RESULTS}

Of a total of 431 patients 65 years or over seen during the period, 173 (40 per cent) were male and 258 (60 per cent) were female. Forty-five (10.4 per cent) were suffering from clinical influenza. The oldest patient seen was 94 years. The table shows the numbers and proportions of those immunised against tetanus and influenza. Males were more likely to have received tetanus vaccine ( 65.3 per cent male, 46.9 per cent female - chi square $13.4, \mathrm{p}<0.01$ ), but there was no significant difference for influenza vaccine (54.3 per cent male, 51.2 per cent female).

Of the 226 patients who had been vaccinated for influenza, only 5 ( 2.2 per cent) presented with clinical influenza. Of the 205 who were not vaccinated for influenza, 40 (19.6 per cent) presented with clinical influenza (chi square $32.8, \mathrm{p}<0.01$ ).

Table 2 shows the age immunisation coverage by age for those 65 years and over. This showed relatively little variation by age.

\section{DISCUSSION}

It is stressed that this was a one-month only preliminary survey to estimate coverage rates. There may be bias due to problems associated with patient recall and record documentation. Nevertheless it showed less than optimal influenza and tetanus coverage rates in the elderly. The number of cases of influenza and tetanus in the elderly warrant a more rigorous approach to improving the coverage rates for immunisation against these diseases. The local general practitioner is in a good position to improve the situation by considering the immune status of people 65 years and over on presentation to the surgery no matter the initial reason for consultation. Consideration might also be given to including promotion of tetanus vaccination in association with the next influenza vaccination campaign.

\section{TABLE 2}

PROPORTION OF PATIENTS 65 YEARS AND OVER EVER IMMUNISED AGAINST TETANUS OR WHO HAD RECEIVED INFLUENZA VACCINE THIS YEAR.

\begin{tabular}{|l|r|r|r|}
\hline & $\begin{array}{r}\text { Tetanus } \\
\text { Vaccination } \\
\text { No. (\%) }\end{array}$ & $\begin{array}{r}\text { Influenza } \\
\text { Vaccination } \\
\text { No. (\%) }\end{array}$ & $\begin{array}{r}\text { Total } \\
\text { Patients }\end{array}$ \\
\hline Male & $113(65.3)$ & $94(54.3)$ & 173 \\
Female & $121(46.9)$ & $132(51.2)$ & 258 \\
Total & $234(54.3)$ & $226(52.4)$ & 431 \\
\hline
\end{tabular}

John Brown, Public Health Nurse, SWSAHS Public Health Unit

Greg Stewart, Medical Officer of Health, SWSAHS Public Health Unit

Mark Harris, Associate Professor of General Practice, UNSW Margaret Coghlan, Registered Nurse, General Practice Unit

1. Morbidity and Mortality Weekly Report. Prevention and Control of Influenza. Vol. 40, May 24, 1991. CDC.

2. Immunisation Procedures. Fourth Edition. 1991. NH\&MRC

3. Public Health Bulletin. Vol 2 No.6 June 1991. NSW Dept. of Health 4. International Classification of Primary Care. Draft Definitions 1991 WONCA.

\section{PUBLIC HEALTH BULLETIN EDITORIAL STAFF}

The Bulletin's editorial advisory panel is as follows: Dr Sue Morey, Chief Health Officer, NSW Health Department; Professor Stephen Leeder, Professor of Community Medicine, University of Sydney; Professor Geoffrey Berry, Professor of Epidemiology \& Biostatistics, University of Sydney; Dr Christine Bennett, Associate Director, Services Planning, Service \& Capital Planning Branch, NSW Health Department; Dr Michael Frommer, Epidemiologist, Epidemiology \& Health Services Evaluation Branch; Jane Hall, Director, NSW Centre for Health Economics, Research and Evaluation, Department of Community Medicine, Westmead Hospital; and Michael Ward, Manager, Health Promotion Unit, NSW Health Department.

The editor is Dr George Rubin, Director, Epidemiology \& Health Services Evaluation Branch, NSW Health Department. Please send your articles, news, comments or letters to him at Locked Bag 961, North Sydney NSW 2059 or fax (02) 3919232 . Suggestions for improving the content of the Bulletin are welcome.

Design - Health Public Affairs Unit, NSW Health Department. 